\title{
The epidemiology of swine influenza
}

\author{
Yin $\mathrm{Li}^{1,2^{*}}$ (D) and lan Robertson ${ }^{1,3,4}$
}

\begin{abstract}
Globally swine influenza is one of the most important diseases of the pig industry, with various subtypes of swine influenza virus co-circulating in the field. Swine influenza can not only cause large economic losses for the pig industry but can also lead to epidemics or pandemics in the human population. We provide an overview of the pathogenic characteristics of the disease, diagnosis, risk factors for the occurrence on pig farms, impact on pigs and humans and methods to control it. This review is designed to promote understanding of the epidemiology of swine influenza which will benefit the control of the disease in both pigs and humans.
\end{abstract}

Keywords: Swine influenza, Influenza, Risk factors, Epidemiology, Zoonotic transmission

\section{Introduction}

Swine influenza (SI) is a respiratory disease of pigs caused by influenza A viruses. The typical clinical signs associated with the disease include coughing, laboured breathing, nasal discharge, sneezing and pyrexia (Kothalawala et al. 2006) and lesions of pneumonia may be observed in infected pigs at slaughter (Karasin et al. 2000; Vincent et al. 2008; Rose et al. 2013). Reproductive problems, including abortion and stillbirths, have also been reported in sows infected with swine influenza virus (SIV) (Wesley 2004). Subclinical infection is common, especially in herds with antibody against homologous SIV strains (Choi et al. 2004; Rose et al. 2013; Hemmink et al. 2016).

Influenza A viruses belong to the Orthomyxoviridae family, which are enveloped viruses containing eight single strand RNA segments. Subtypes of influenza A viruses are determined by antigenic and genetic properties of two major viral envelope proteins: hemagglutinin (HA) and neuraminidase (NA) (Hause et al. 2014). Currently, there are 18 HAs (H1-H18) and 11 NAs (N1N11) recognised, with H17-18 and N10-11 types having only recently been isolated from bats (Mehle 2014).

\footnotetext{
* Correspondence: yin.li@csiro.au

${ }^{1}$ School of Veterinary Medicine, Murdoch University, Perth, WA, Australia

${ }^{2}$ Commonwealth Scientific and Industrial Research Organisation, St. Lucia, QLD, Australia

Full list of author information is available at the end of the article
}

Influenza A viruses are the most clinically important influenza viruses as they can cause serious disease in a wide range of species, including humans, pigs, birds, horses, cattle, whales, seals, tigers, dogs, cats and ferrets (Mehle 2014). There are three other genera of influenza viruses: Influenza $B, C$ and $D$. Influenza $B$ viruses have mainly been isolated from humans and seals (Osterhaus et al. 2000). Influenza $C$ viruses are primarily found in humans, pigs and dogs, and influenza $\mathrm{D}$ has recently (2011) been detected in pigs and cattle (Hause et al. 2014; Luo et al. 2017).

Most avian influenza viruses' HA bind specifically with $\alpha-2,3$-galactose sialic acid, which is abundant in epithelial cells of avian trachea, while most human influenza viruses prefer $\alpha$-2, 6-galactose sialic acid linkage, which is abundant in epithelial cells of human trachea. However epithelial cells of pig trachea have both $\alpha-2,3-$ and $\alpha-2,6$-galactose sialic acid linkages, and so pigs can be susceptible to both avian and human influenza viruses (Ito et al. 1998). Pigs are believed to act as a "mixing vessel" for swine, avian and human influenza viruses allowing the production of reassortant influenza viruses.

Swine influenza has huge economic impact on pig industry as it is prevalent and can cause serious loss when associated with other disease (Lin et al. 2016; Rech et al. 2018). In addition, the disease is also a zoonosis. Despite the potential impact of SIV on the pig industry and 
public health, SI is often neglected by the pig industry workers. The main reason for this is that many of infections in pigs are subclinical or mild and hence easily overlooked (Detmer et al. 2013). Furthermore, although the morbidity of SIV infection in a herd can be as high as $100 \%$, mortality is usually extremely low (Er et al. 2014). Although many studies has been carried out on SI at molecular level, there are still knowledge gaps in this disease (Li et al. 2020b; European Union 2021). For example, what have facilitate the spill-over infection to human? What are the environmental and anthropological risk factors for SI infection in pigs and human? More research especially epidemiological studies are needed to answer these questions.

\section{Swine influenza viruses}

\section{Characteristics of swine influenza viruses}

As a member of the influenza A virus group, SIV is an enveloped virus with eight segments of RNA (HA, NA, PA, PB1, PB2, NP, M and NS) (Reeth et al. 2012). The infectivity of the virus is mainly determined by two proteins, HA and NA. HA can bind receptors in host and facilitate virus invasion into host cell while NA is typically responsible for cleaving sialic acid so the reproduced virus particles can release (David et al. 2020). However, NA may also contribute to binding host cells (Benton et al. 2017).

Influenza viruses are sensitive to environmental conditions. Chemical disinfectants such as $0.1 \mathrm{~mol} / \mathrm{L} \mathrm{NaOH}$, $70 \%$ ethanol, 70\% 1-propanol and ethylene oxide can effectively inactivate them (Jeong et al. 2010). One study reported that even a powdered laundry detergent with peroxygen (bleach) was sufficient to kill the virus (Lombardi et al. 2008). However, the inactivating efficiency of many disinfectants is reduced at low temperatures and in environments contaminated with organic material, and consequently, caution is needed when disinfecting SIV-infected premises during winter and organic matter should be removed prior to disinfection (Haas et al. 1995; Botner and Belsham 2012). The infectivity of SIV can be retained for more than six weeks in slurry at $5^{\circ} \mathrm{C}$, whilst at $20^{\circ} \mathrm{C}$ it can remain viable for up to 14 days (Botner and Belsham 2012).

\section{Subtypes and genetic recombination among strains}

Many subtypes of influenza A virus have been isolated from pigs and continue to circulate and diversify (Lewis et al. 2016). Among these subtypes, the most common SIVs circulating in pig populations are subtypes H1N1, H3N2 and H1N2. The dominant strains in the USA are 1A classic $\mathrm{H} 1 \mathrm{~N} 1$, triple reassortant $\mathrm{H} 3 \mathrm{~N} 2$, 1C avian-like swine H1N1 and pandemic A/H1N1 2009 (1A H1N1pdm09) virus (Bowman et al. 2014b). In contrast, in Europe the dominating strains are $1 \mathrm{C}$ avian-like swine
H1N1, 1B human-like reassortant swine H1N2, humanlike reassortant swine H3N2, and 1A H1N1pdm09 virus (Simon et al. 2014; Watson et al. 2015b; Anderson et al. 2016); however in China all of the lineages from both the USA and Europe have been shown to be circulating in pig population (Chen et al. 2014a; Xie et al. 2014; Yang et al. 2016).

Co-circulation of different SIV strains is commonly seen in piggeries. Active surveillance undertaken in the USA reported simultaneous infection with influenza $\mathrm{H} 3 \mathrm{~N} 2$ and H1N1pdm09 virus in 8 different age categories of pigs from four to over 24 weeks of age (Corzo et al. 2013a). Another study in Italy reported infection with multiple reassortant genotypes of $\mathrm{H} 1 \mathrm{~N} 2$ in one local commercial breeding farm (Beato et al. 2016). In south China, $24 \%$ pigs tested from seven of nine counties surveyed were positive for both H1 and H3 (Song et al. 2010).

The coexistence of different SIV strains within individual pigs facilitates gene reassortment and emergence of new strains. A cohort study in three selected farrow-tofinish pig farms in France found that H1N1 and H1N2 viruses could simultaneously existed in the same farm, batch or even individual pigs, and reassortants between viruses from these lineages could be isolated from infected herds (Rose et al. 2013). After the pandemic of "swine flu" in 2009, gene reassortment between H1N1pdm09 viruses and local endemic swine viruses were identified in many countries, including the USA, Brazil, Germany, Italy, UK, Vietnam, Thailand, Japan, Korea and China (Abe et al. 2015; Kong et al. 2015). Whole-genome phylogenetic analysis of 368 influenza A viruses circulating in the USA has demonstrated the presence of 44 different genotypes of H3N2 from 2009 to 2016, with the majority of these genotypes containing at least one gene segment from H1N1pdm09 (Rajao et al. 2017).

Swine influenza virus reassortants can become endemic in pig farms and potentially transmit to humans, resulting in pandemic circulation. The best-known example is $2009 \mathrm{H} 1 \mathrm{~N} 1$ pandemic influenza A virus involving a reassortment of three different influenza strains circulating in pigs, birds and humans (van der Meer et al. 2010). Shortly after the outbreak of H1N1 in the USA, H1N1pdm09 virus was found in pig and human population all over the world. A survey undertaken in north Vietnam in 2009 reported a maximum seroprevalence of $\mathrm{H} 1 \mathrm{~N} 1 \mathrm{pdm} 09$ of $55.6 \%$ (95\% CI: 38.1-72.1) in pigs sampled at a slaughterhouse, with a farm-level seroprevalence of $29 \%$ (95\% CI, 23.2-35.7) (Trevennec et al. 2012). In China, H1N1pdm09 virus was also first isolated in pigs in 2009, and reassortants with internal genes from the pandemic 2009/H1N1 viruses were found in pigs in the following years (Chen et al. 2013; 
Chen et al. 2014b; Qiao et al. 2014). H3N2 variants containing genes from H1N1pdm09 influenza virus were subsequently isolated from at least seven countries between 2009 and 2013, and it seems to be the most commonly emerging SIV genotype (Kong et al. 2015). It was suspected that H1N1pdm09-origin internal gene segments had fitness advantage over the segments of other SIV's in terms of contributing genes for new reassortants (Kong et al. 2015).

\section{Distribution of swine influenza}

Swine influenza was first observed in 1918 in the USA, Hungary and China (Brown 2000), and today it is one of the most ubiquitous diseases circulating in the global pig population. Corzo et al. (2013a) reported an individual prevalence level of $4.6 \%$ in the USA pig population, and a $90.6 \%$ herd prevalence in the participating farms with a period of 12-24 months using a real-time reverse transcription polymerase chain reaction (real-time RT-PCR). A cross-sectional study in northern Mexico reported that more than 50\% samples tested from commercial farms with between 300 and 2500 sows were seropositive to either $\mathrm{H} 1$ or $\mathrm{H} 3$ subtype SIV (Lopez-Robles et al. 2014). However, the seroprevalence may have been overestimated because these authors primarily sampled pigs less than ten weeks of age and maternally derived antibody (MDA) can last up to ten weeks in pigs and potentially have resulted in false positive results (Cador et al. 2016). This assumption was also supported by the finding of decreasing antibody titres with increasing age of the sampled pigs. The authors also reported that $16.7 \%$ (25/150) sampled pigs were positive for type A influenza with a RT-PCR test (Lopez-Robles et al. 2014).

Swine influenza is also widespread in Europe. In study in Belgium, France, Italy and Spain, 80 farrow-to-finish farms were monitored from 2006 to 2008. Ninety percent farms were classified as positive for SIV, with an individual level seroprevalence of $62 \%$. Forty-nine percent of farms were infected with one subtype, 38\% with two subtypes and 3.9\% with three subtypes of SIVs (Kyriakis et al. 2013). However in this study, the sampling was also biased, resulting in potential overestimation of the prevalence as farms sampled were selected from areas with a high density of pigs or contained pigs that had a history of respiratory problems. An analysis of historical surveillance data in Norway showed that the national herd seroprevalence of influenza $\mathrm{A}(\mathrm{H} 1 \mathrm{~N} 1) \mathrm{pdm} 09$ virus was around $43 \%$, and the individual pig prevalence of pandemic $\mathrm{H} 1 \mathrm{~N} 1$ in infected farms was more than $60 \%$ (Er et al. 2016a). Another study in Spain in 2009, that involved sampling pigs from 98 randomly selected pig farms, reported a farm-level seroprevalence of nearly $100 \%$ with an animal level seroprevalence of $62.3 \%$ (Simon-Grife et al. 2011). In England, a 52\% herd prevalence was reported by Mastin et al. (2011), with the highest individual prevalence of $33 \%$ being reported in sows.

Swine influenza is enzootic in the Chinese pig population, with many subtypes contemporarily circulating on farms. Serological evidence indicateed the presence of $\mathrm{H} 1, \mathrm{H} 3, \mathrm{H} 4, \mathrm{H} 5, \mathrm{H} 7$ and $\mathrm{H} 9$ influenza viruses in pig populations in the country (Ninomiya et al. 2002; Liu et al. 2011; Yu et al. 2011; Ding et al. 2021). SI is also prevalent in pig populations in other countries in South East Asia (Lewis et al. 2016). H1N1, H1N2 and H3N2 subtypes are cocirculating in pig population in Vietnam, and spill-over infection of human origin influenza viruses to pigs were detected. Notably, some SIV reassortants had infected humans (Takemae et al. 2017; Baudon et al. 2018; Takemae et al. 2018; Baudon et al. 2020). Similarly, the three subtypes are also prevalent in the pig population of Thailand and $\mathrm{A}(\mathrm{H} 1 \mathrm{~N} 1) \mathrm{pdm} 09$ and its reassortants are found as the predominate strains in the field (Nonthabenjawan et al. 2015; Mine et al. 2019; Nasamran et al. 2020).

\section{Diagnosis of swine influenza Serological methods}

Serological tests for SIV mainly target host antibodies against the virus. The most commonly used serological tests are hemagglutination inhibition (HI) test and enzyme-linked immunosorbent assay (ELISA). Many commercial ELISA kits have been developed to detect antibody to influenza A nucleoprotein (NP) because it is highly conserved in influenza A viruses (Goodell et al. 2016). Several studies have shown that an NP blocking ELISA kit for testing antibodies in birds can also be used to detect NP antibodies in pigs (Nava et al. 2013; Goodell et al. 2016). In general, $\mathrm{HI}$ tests are simpler to operate, cheaper and quicker than ELISAs; however choice of antigen is complex because of the diversity of SIV. In addition, the sensitivity of $\mathrm{HI}$ test can be low if used solely for SIV surveillance when heterologous viruses are present (Goodell et al. 2016), although they do offer the advantage that they can be used for subtyping viruses (Van Reeth et al. 2006). It worth noting that red blood cells from different species such as chicken, turkey and guinea pig can be used for HI test, and the erythrocyte species can impact titers of HI test against SIVs (Wiriyarat et al. 2010; Ovsyannikova et al. 2014; Trombetta et al. 2018).

Serological surveys/tests often take advantage of existing collections of serum samples, as collecting blood samples involves significant cost, time and labour inputs. To overcome this, a new method targeting the antibody in the oral fluid of swine, using a NP-blocking ELISA, has been developed (Panyasing et al. 2014). This test would only give a population-level assessment of a herd. 
With experimentally infected pigs, NP antibodies in the oral fluid were detected 7 to 42 days post-infection in all challenged groups. The oral fluid versus serum sampleto-negative $(\mathrm{S} / \mathrm{N})$ ratios from pigs in the same pen showed a correlation of 0.796 , indicating good agreement between results for testing oral fluid samples and serum samples (Panyasing et al. 2014). In contrast, another study that used field-collected oral samples found that NP blocking ELISA had a much lower sensitivity in 10-14-week-old pigs compared with matched serum samples $(19 \%$ for oral fluid and $93 \%$ for serum, $P<0.01)$ (Gerber et al. 2017).

There are several advantages with using serological tests: firstly, they are often inexpensive; secondly, they are easier to perform compared with polymerase chain reaction (PCR) tests or virus isolation (VI); and thirdly, serological tests are more sensitive in detecting exposure of pigs to influenza A virus than PCR tests or virus isolation because the antibodies can last for at least 1.5 months post-infection, and consequently, serological tests are less sensitive to the sampling time (Goodell et al. 2016). However serological tests have limitations which include: they only provide information on historical exposure to SIV and do not provide viral genetic information or live viruses which are vital for evaluating the potential pandemic threat of strains; cross-reactions can occur between different lineages within one subtype, or even among different subtypes; and maternally derived antibodies may interfere with the accuracy of the test (Allerson et al. 2013a; Detmer et al. 2013).

\section{Molecular methods}

Molecular tests of nasal swabs, nasal wipes or oral fluids are mainly used in surveillance to detect the presence of SIV RNA and to produce amplicons for further sequencing. Conventional molecular assays for influenza A viruses target a conserved amplicon of $\mathrm{M}$-gene. For subtyping, specific primers need to be designed to detect different gene segments, mainly $H A$ and $N A$ (Henritzi et al. 2020). Universal primers can also be used to amplify cDNA, which is then sequenced (Inoue et al. 2010).

Real-time RT-PCR assays for SIVs detection were first developed in 2004 (Richt et al. 2004). Compared with conventional RT-PCR, it can be performed in a shorter time (within a few hours) and can differentiate SIV subtypes. It can also be less expensive than VI and conventional RT-PCR assays. Most importantly, real-time RTPCR doesn't require post-PCR sample handling, thus reducing the potential for cross-contamination (Richt et al. 2004).

For public health purposes, detection of coinfection with different virus strains in a pig herd would be very valuable in SIV surveillance. Multiplex RT-qPCR assays can differentiate H1, H3, N1 and N2 SIV subtypes.
These multiplex RT-qPCR assays can also identify different lineages within $\mathrm{H} 1$ subtype, such as $1 \mathrm{C}$ "av" (European avian-derived), 1B "hu" (European human-derived) and 1A "pdm" (H1N1pdm09). Henritzi et al. (2016) reported that multiplex RT-qPCR assays that they developed could detect double infections with different lineages in one clinical sample. However, efficiency of RT-qPCR relies heavily upon the specific primers having no mismatches with target amplicon sequence, with outdated primers resulting in low test sensitivity (Yang et al. 2014). Since the primers used by Henritzi et al. (2016) were designed specifically for SIV strains circulating in Europe, whether these RT-qPCR assays could be used for SIV surveillance in other regions/continents requires further study.

\section{Virus isolation}

Isolation of SIV is undertaken routinely in embryonated chicken eggs (ECEs) and various cell lines, including Madin-Darby canine kidney (MDCK) and CACO-2 cell line (Chiapponi et al. 2010). It has been reported that sensitivity of SIV isolation with different methods is dependent upon the virus strains present. A study using strain A/Swine/Indiana/1726/88 (H1N1) showed that ECE was more sensitive than MDCK cell line (Clavijo et al. 2002). In contrast, in another study with clinical samples, use of MDCK cell line resulted in recovery of more isolates of $\mathrm{H} 1 \mathrm{~N} 2$ and $\mathrm{H} 3 \mathrm{~N} 2$ than with ECE (Bowman et al. 2013), whilst CACO-2 line was shown to be more sensitive $(p<0.01)$ for the isolation of H1N1 and H1N2 subtypes in Italy compared to both MDCK cells and ECEs (Chiapponi et al. 2010). However for H3N2 virus, isolation in ECE has been demonstrated to be better than in cultured cells $(\mathrm{p}<0.01)$ (Chiapponi et al. 2010).

VI is often difficult, expensive and time consuming, but it is necessary when the live virus is required for further research, such as evaluating the pathogenicity of new SIVs and screening for vaccine candidate strains (Detmer et al. 2013).

In conclusion, serological tests can be used in SI surveillance to tell exposure history of pigs to influenza virus; PCR tests are more suitable for detecting the presence of SIVs and the acquired gene material can be used for molecular studies; VI is often necessary if live viruses be needed for further research such as vivo test and vaccine development.

\section{Epidemiology}

Swine influenza is endemic in many countries in North and South America, Europe, Asia and Africa (Almeida et al. 2017). Infection in pig farms can be seen throughout the year, although an increased number of cases are often seen in spring and winter (Beaudoin et al. 2012; 
Kyriakis et al. 2013). It is believed that commercial pig farms have a higher risk of infection compared to backyard farms, especially for infection with new SIV reassortants (Gonzalez-Reiche et al. 2017). Farrow-to-finish pig farms are more susceptible to SIV infection than fattener enterprises because they continuously produce naïve piglets (Loeffen et al. 2003; Kyriakis et al. 2013). In an infected herd, sows have the highest risk of being seropositive, most likely linked to their older age resulting in greater opportunity for exposure to the virus, while the greatest chance of isolating live viruses is from piglets (Mastin et al. 2011; Takemae et al. 2011; Ozawa et al. 2015; Er et al. 2016a).

Virus transmission between pigs is mainly through direct pig-to-pig contact. Aerosol transmission is one of the common ways of indirect transmission of SIV (Brown 2000; Corzo et al. 2013b; Hemmink et al. 2016). A pig farm can become infected through the introduction of carrier pigs or entry of the virus on infectedvisitors, or on vehicles or other fomites (Simon-Grife et al. 2011; Allerson et al. 2013b; Er et al. 2016a), highlighting the importance of strict farm biosecurity.

In infected pigs, SIV is excreted in oral and nasal secretions, with no virus shed in the faeces (Choi et al. 2004; Botner and Belsham 2012). Pigs can start to shed virus within 2 days of infection. Although the duration of shedding is usually 8 to 10 days, shedding for more than 30 days has been reported (Choi et al. 2004; Botner and Belsham 2012). The reason for a long shedding period has been postulated to be linked to the suppression of immunity in infected pigs (Choi et al. 2004).

Between individual pigs within a herd, the transmission of SIV can be rapid. Rose et al. (2013) reported that in farrow-to-finish pig farms with recurrent influenza outbreaks and no prior immunity, the basic reproduction value (R0) was high, between 2.5 and 6.9.

\section{Interspecies transmission}

HA subtypes circulating between birds, pigs and humans include $\mathrm{H} 1-\mathrm{H} 16$, with different subtypes predominantly circulating in individual species. Wild waterfowl are the natural reservoir of $\mathrm{H} 1-\mathrm{H} 16$, while domestic chickens are mainly infected by $\mathrm{H} 5, \mathrm{H} 7$ and $\mathrm{H} 9$ subtypes. For humans and pigs, the most common circulating subtypes are $\mathrm{H} 1-\mathrm{H} 3$ and $\mathrm{H} 1$ and $\mathrm{H} 3$, respectively (Short et al. 2015). Pigs can contract influenza A viruses from other species, especially from infected humans and birds (Karasin et al. 2000; Grontvedt et al. 2013; Nelson and Vincent 2015).

Avian influenza viruses have been isolated from pigs in many countries and regions. In Canada, H4N6 was isolated from pigs with pneumonia on a commercial swine farm and similarly an avian-origin H4N6 was isolated from pigs displaying clinical respiratory signs in the USA in 2015 (Karasin et al. 2000; Abente et al. 2017). A study in Nigeria reported that 22 of 129 samples collected from apparently healthy pigs were positive to H5N1. At the same time, sampling there showed an incursion of highly pathogenic avian influenza (HPAI) H5N1 in local poultry (Meseko et al. 2018). In addition, both avian $\mathrm{H} 9 \mathrm{~N} 2$ and $\mathrm{H} 5 \mathrm{~N} 1$ viruses were detected in pigs in Egypt in 2014 and 2015 (Gomaa et al. 2018). In China, 28 isolates of H9N2 were detected in pigs from 1998 to 2007 (Yu et al. 2011). The isolates of H9N2 AIVs recently detected circulating in poultry farms in south China have shown increased ability to replicate in pigs than did earlier isolates (Sun et al. 2019), highlighting the greater risk of new viral reassortants appearing in this location.

In pigs, infection with human origin influenza A virus appears to be more common than that from avian-origin influenza A virus (Nelson and Vincent 2015). A study in the Czech Republic reported the presence of antibodies against human influenza virus isolated during the 1995 epidemic in local pig population. It is possible that the human virus was introduced to pig herds by infected animal attendants, in whom antibodies against this virus were also found (Pospisil et al. 2001). In China, former prevailing human H1N1 strains have also been found to be circulating within pig population (Yu et al. 2009) and phylogenetic analysis indicated that infection arose through transmission from humans to pigs. It was interesting that in that study, 4 out of 5 virus isolates were from Guangdong province. This may be either because Guangdong actually had more pig infections arising from human influenza than other provinces, or that Guangdong had contributed more of the 500 tested samples. Although the samples were sourced from 8 different provinces, unfortunately the actual sample size from each province was not given (Yu et al. 2007). Introductions of human seasonal influenza viruses into pigs from 1965 to 2013 has been summarized by Nelson et al. (2015a), and the authors concluded that more than 40 cases of human-origin H1N1 viruses in pigs had been reported in the 5 years after H1N1pdm09 was initially detected in humans. H3N2 viruses closely related to human viruses that circulated in 2010 have also been found in pigs from Central America in 2010 (GonzalezReiche et al. 2017).

Many researchers believe that most subtypes of influenza A viruses from other species are capable of transiently infecting pigs. However, as the majority of these strains have not been repeatedly detected in the same pig farms or in samples collected from pigs processed at slaughterhouses, it is assumed that they are not able to establish in pig population (Pospisil et al. 2001; Vijaykrishna et al. 2011; Li et al. 2015). 


\section{Risk factors for SIV infection on pig farms Husbandry factors}

Some management and husbandry practices are associated with SIV infection in pig farms. For example, piggeries that failed to prevent the entry of wild birds (OR 2.50, 95\% CI: 1.01-6.16) and keeping poultry on the farm (OR 3.24, 95\% CI: 1.52-6.94) were shown to increase the risk of SI infection in pig farms in South China (Li et al. 2019). Larger farms have been reported to have an increased risk of infection than smaller herds (Mastin et al. 2011; Takemae et al. 2016; GonzalezReiche et al. 2017). A high density of weaners has also been shown to increase the risk of infection in herds (OR: 2.9; 95\% CI: 1.2-7.0), as has failure to adopt an allin all-out practice in the fattening room $(\mathrm{OR}=2.4,95 \%$ CI: 1.0-5.8) (Fablet et al. 2013). Another study reported that herds with a high number $(>18)$ of finishers per water space had an increased risk of infection (OR 5.22; 95\% CI: 1.57-17.43) compared to herds with lower numbers of pigs $(\leq 18)$ per water space (Mastin et al. 2011). In addition, one study found that the presence of open partitions between pens increased the risk of infection (Simon-Grife et al. 2011), most likely associated with increased contact opportunities between pigs. Other factors which have also been linked with an increased risk of SIV infection in pig herds include increased replacement rates in pregnancy units, farm type (farrow-to-finish and breeder herds had a higher risk of SI infection than finisher farms), having a suckling period of less than 28 days (for prevalence in weaners) and a fully slatted floors in pens (Simon-Grife et al. 2011; Baudon et al. 2017). Low room/ambient temperature $\left(<25^{\circ} \mathrm{C}\right)$ in farrowing room has also been reported to increase the risk of infection (Fablet et al. 2013). In the United Kingdom, intensively housed (indoors) pigs had a higher risk of SIV infection than farms adopting extensive or outdoor housing (Mastin et al. 2011). Similarly the use of straw yards in UK farms has been shown to reduce the risk of infection (Mastin et al. 2011; Fablet et al. 2013). In conclusion, the husbandry and management practices that would facilitate interactions between naïve pigs and those that would result in stress to pigs are potential risk factors for SI infection in pig farms.

\section{Biosecurity factors}

Poor biosecurity nearly always leads to a higher risk of a range of diseases (Robertson 2020), including SI (Filippitzi et al. 2018). Some biosecurity factors have been reported to be associated with increasing SIV infection in pig farms. Firstly, frequent human-pig interaction increases the potential spillover of human influenza viruses from humans to pigs. One study in China found that although local pig industry workers had extensive close contacts with pigs, they had limited knowledge and awareness that SIV could infect humans (Li et al. 2020a). One study demonstrated that the presence of farm staff with influenza-like illness was significantly associated with the presence of SIV on pig farms in Norway (OR = 4.15, 95\% CI 1.5-11.4, $p=0.005$ ) (Grontvedt et al. 2013). A lower herd-level seroprevalence in Norwegian fattening herds was believed to be associated with fewer close human-pig interactions, in contrast to sow (breeding) herds which had the highest seroprevalence because sows frequently contacted with many different people (Er et al. 2016a). Secondly, uncontrolled access to the farm by vehicles or visitors can increase the chance of introducing diseases through contaminated vehicles, clothing, footwear and fomites. It was found to be a risk factor for H1N1 seropositivity $(\mathrm{OR}=2.44,95 \% \mathrm{CI}$ : 1.01 5.87) in a study conducted in Spain (Simon-Grife et al. 2011). A third factor is disease management within the farms. Mastin et al. (2011) reported that the management of the sick pen was important; stating that the location of sick pens in a separate building to those housing healthy pigs may help reduce SIV infection, although this was not confirmed through a formal study. However, as with most infectious diseases, isolation of affected animals is a key management procedure to minimise transmission to other animals and contamination of environment (Cui and Chen 2017; Robertson 2020).

Most of the studies on risk factors for infection with SI have found agreement in risk and protective factors, although some studies did generate conflicting results. For example, Simon-Grife et al. (2011) reported that the presence of other species, such as cats, dogs, birds or cattle, on the farm increased the infection risk; in contrast Takemae et al. (2016) found that the presence of other animals on the farm was potentially protective. These conflicting results may be due to the different ecosystems and the different husbandry practices adopted in the surveyed herds, different populations under study or differences in the case definitions used in the individual studies.

\section{Environmental factors}

Environmental factors for SIV infection have rarely been studied. However, the density of pig farms in an area appears to be a risk factor for SIV infection. Using machine learning modelling, one study in south China showed that pig density is one predictor variable for three influenza infection scenarios in pigs (infection with human strains, infection with avian strains, and coinfection with H9N2 avian strain and at least one swine strain) (Ding et al. 2021). Pasma (2008) analysed H3N2 SI outbreaks in Canada during the autumn of 2004 and found clustering of outbreaks in a region with a high pig density. It was hypothesized that the density of pig farms was a factor in clustering and spread of this outbreak, although 
the data didn't show statistical significance for this factor. Couacy-Hymann et al. (2012) also thought low pig density in Côte d'Ivoire, Benin, and Togo might be the reason for low prevalence of avian and swine influenza in those three African countries. In addition, Ding et al. (2021) demonstrated that other environmental factors, including chicken density, duck density, human population density, annual cumulative precipitation and elevation, were predictor variables for infection of pigs with human/poultry influenza viruses.

Some studies on avian influenza have highlighted the role of environmental and meteorological factors in avian influenza outbreaks. Potential risk factors, such as monthly average rainfall in the preceding 3-7 months, being close to rivers, lakes or seacoasts, low ambient air temperature, and high relative humidity have been reported to be linked with avian influenza outbreaks (Fang et al. 2005; Si et al. 2013; Zhang et al. 2014; Ferenczi et al. 2016). Since pigs may also contract avian-source influenza viruses, these environmental and meteorological factors could also be potentially associated with outbreaks of SI and require further investigation. The study of Ding et al. (2021) offered evidence to support this hypothesis.

\section{Impact of swine influenza on the pig industry Morbidity and mortality}

Swine influenza is a highly contagious disease with almost $100 \%$ exposed pigs becoming infected, although the mortality rate is usually very low. Even with infection in a naïve pig population, clinical signs may only be observed in a small proportion of pigs. Er et al. (2014) reporting that less than $7 \%$ pigs displayed clinical signs in an outbreak of a boar testing station in Norway.

However serious morbidity and mortality, associated with economic losses can occur when SIV simultaneously infects pigs with other swine diseases or when infection occurs in sows during the late stages of pregnancy (Fablet et al. 2012). A study reported that coinfection with Mycoplasma hyopneumoniae exacerbated the clinical effects of H1N1 infection (Deblanc et al. 2013). Wesley (2004) observed stillbirths in naturally infected gilts after challenge with live H3N2 SIV at 80 to 82 days of gestation. The average percentage of stillbirths was $22 \%$ per litter while the control gilts (also naturally infected but not challenged with live H3N2 SIV) had no stillbirths. Furthermore, abortions can also occur when sows are infected with new emerging strains of SIV (Gumbert et al. 2020).

\section{Productivity losses}

The productivity losses caused by SIV infection include decreased feed conversion efficiency (FCE) and slower growth of pigs. Er et al. (2014) recorded an outbreak of
H1N1pdm09 in a Norwegian boar station and analysed the infection on production performance in the resident pigs. Their study showed that seropositive and viruspositive pigs overall had reduced $(P<0.05)$ growth performance compared to seronegative pigs, even though the feed intake was not decreased. For seropositive pigs, the negative effect on growth performance was seen during growth from 81 to $100 \mathrm{~kg}$ (GF3), whereas FCE was reduced requiring an extra $0.029 \mathrm{~kg}$ of feed for every 1 $\mathrm{kg}$ of weight gain and the average daily growth (ADG, weight gain in $\mathrm{kg} /$ day) decreased an average of $0.015 \mathrm{~kg} /$ day. For virus-positive (with RT-PCR test) pigs, infection reduced ADG by 0.058 to $0.015 \mathrm{~kg} /$ day and also reduced FCE (an extra 0.058 to $0.125 \mathrm{~kg}$ of feed required for each $\mathrm{kg}$ of weight gain). Thus, infection resulted in an additional $2.3 \mathrm{~kg}$ and $5.9-8.0 \mathrm{~kg}$ feed for seropositive pigs and virologically positive pigs to reach $100 \mathrm{~kg}$ bodyweight, respectively. The virus-positive pigs also took an extra 1.6 to 2.4 days to reach $100 \mathrm{~kg}$ bodyweight. This delay in reaching market weight would also increase the cost of the disease.

Er et al. (2016b) estimated that a batch of 150 pigs infected with H1N1pdm09 in Norway would consume an extra 835 (fifth percentile) to $1350 \mathrm{~kg}$ (95th percentile) feed and take 194 (fifth percentile) to 334 (95th percentile) more pig days to reach expected body weights than an uninfected batch of 150 pigs. They also found that infection in the late stage of fattening could induce the greatest losses.

\section{Impacts on public health}

Swine-source influenza outbreaks and its prevalence in human

SIVs have a distinct impact on the potential for pandemic influenza in humans with 19 influenza A virus reassortants emerging in humans since 1918. Of these, three were predominantly zoonotic swine influenza A virus variants (Bui et al. 2017). Several swine-to-human spillover infections have been reported in China, as well as in other countries. One child infected with swine influenza H3N2 virus was reported in Hong Kong in 1999 (Gregory et al. 2001). Zu et al. (2013) reported a human case infected by European avian-like swine H1N1 influenza virus in Jiangsu province, with the same virus being isolated from the patient's pigs in a smallholding belonging to the patient. Killian et al. (2013) investigated an outbreak of H1N1 at an Ohio county fair in the USA in 2007 and detected a triple-reassortant swine H1N1 influenza virus that had infected both people and pigs.

Human-adapted SIVs can result in pandemic circulation. The H1N1pdm09 affected 10-20\% of humans globally and was a new strain incursion into swine and humans (Garten et al. 2009; Short et al. 2015). In Mexico in the period 2007-2008, 12.9 and $3.2 \%$ pig farm 
workers were seropositive to H3N2 and H1N1 SIV, respectively (Lopez-Robles et al. 2012). Ma et al. (2015) reported that in China, 17.3 and $7.0 \%$ workers in piggeries and workers in other occupations, respectively were also seropositive to swine H3N2 virus. However, crossreactions between antibodies against human seasonal $\mathrm{H} 3 \mathrm{~N} 2$ and swine H3N2 can hamper interpretation of results. These studies did not rule out this possibility, and in another study, the authors found seropositivity against seasonal H3N2 virus was a significant risk factor for workers being seropositivity to swine H3N2 virus (Ma et al. 2015).

\section{Pathogenicity and transmission to humans}

Although several human deaths have resulted from SIV infection (Tang et al. 2010; Short et al. 2015), the majority of SIV human infections are mild and indistinguishable from other seasonal influenza virus infections. Influenza $\mathrm{H} 1 \mathrm{~N} 1 \mathrm{pdm} 09$ and $\mathrm{H} 3 \mathrm{~N} 2$ virus variants in the USA are the most recent swine-origin influenza viruses. Human mortality of influenza H1N1pdm09 was approximately 29 deaths per 100,000 infections, and among the 350 human cases of H3N2 variants, only one patient with unspecified concurrent diseases died (Tang et al. 2010; Short et al. 2015). Similar spill-over infection from pig to human were also reported in Europe. In 2016, a child in the Netherlands was infected by swine influenza A (H1N1) via contacting pigs (Fraaij et al. 2016). Another case was reported in Italy and the patient also had severe infection (Rovida et al. 2017). It worth noting that the two patients got severe syndromes, although all of his close contacts were not infected.

\section{Infection pathways: risk factors for human infection}

The most common pathway for swine-to-human spread of SIV is exposure to live pigs. A study reported that exposure to pigs increased the chance of humans being infected with H3N2 SIV (OR=3.05, 95\% CI: 1.65-5.64) and working in large breeding herds also increased the likelihood of detecting anti-SIV antibodies in pig farm workers (OR $=3.98,95 \%$ CI: 1.00-15.86) (Lopez-Robles et al. 2012). A study in the USA reported that there were spatio-temporal associations between the number of pig farms within counties and the timing of human flu cases, with peak number of cases during years when SIV was present, indicating transmission between pigs and humans (Bowman et al. 2014a; Lantos et al. 2016).

\section{Prevention of spillover of SIVs to humans}

As the circulation of influenza A viruses among pigs and humans is very complicated in terms of the interaction of the two species in different ecosystems, it is difficult to recommend effective measures to prevent the transfer of infection from pigs to humans. Dorjee et al. (2016) used mathematical modelling to demonstrate that minimizing influenza transmissibility at pig-human interface through good personal hygiene, avoiding direct contacts with sick pigs, and targeted vaccination of swine workers with protective vaccine strains had significant beneficial effects on reducing spillover to humans. They also evaluated different strategies to minimize the duration and size of outbreaks if a spillover event happened, and suggested that early detection and effective quarantine in humans had the greatest impact on the control of influenza spread. Their findings support putting more emphasis on early detection of SIVs with pandemic potential in pigs, and hence the need for strengthening the monitoring of gene recombination among SIVs. Previous studies in south China showed that SIV and human/avian influenza viruses were circulating in local pig population simultaneously, and workers in the local pig industry adopted minimal selfprotection measures while contacting pigs due to insufficient knowledge about SI (Li et al. 2019; Li et al. 2020b; Ding et al. 2021). The authors suggested risk-based surveillance and intervention for SI control in south China and targeting of the key counties that supply pigs to live pig markets would help control the transmission of strains to humans (Li et al. 2020c; Ding et al. 2021).

\section{Control measures for influenza in pigs Vaccination}

Vaccination against SI may protect pigs from infection and is commonly used in sows because it is believed piglets are protected through maternal immunity to homologous influenza A virus strains (Chamba Pardo et al. 2019). Allerson et al. (2013a) demonstrated that vaccination of sows could significantly reduce SIV transmission among piglets; however, there are several challenges with SIV vaccination. Firstly, as homologous antibody against circulating strains is vital for the efficacy of vaccination in the field, it is critical to vaccinate with the current circulating strains. However, as different strains are commonly found in herds throughout the world, the failure of vaccination to induce protective immunity by not incorporating homologous local infecting strains in the vaccine cannot be ignored. Secondly, MDA may interfere with immunity against infection with homologous SIV strains in piglets, with one study showing that MDA in piglets could result in a prolonged shedding period of virus when piglets were subsequently infected with homologous SIV strains (Rose et al. 2013). Thirdly, vaccineassociated enhanced respiratory disease were observed in the field, which may further offset the benefit of using SIV vaccine (Mancera Gracia et al. 2020).

\section{Surveillance for swine influenza viruses}

Surveillance programs for SIV have been developed and implemented in many countries. In the USA, the aims of 
SIV surveillance include protection of public health. However; detection, discovery and sharing of virus isolates to facilitate updates for vaccines, refine diagnostic assays, and determine the distribution of new influenza strains in pigs to inform further policy decisions are also advantages of this surveillance (Corzo et al. 2013a; Kaplan et al. 2015). In Europe, the European Surveillance Network for Influenza in Pigs (ESNIP, 2001-2012) was established to "increase the knowledge of the epidemiology and evolution of swine influenza virus in European pigs". Most of the funds associated with this network have been directed towards undertaking research on antigenic and genetic characterization of field isolates of SIV (Detmer et al. 2013; Simon et al. 2014; Watson et al. 2015a).

For the purpose of preventing potential pandemic human influenza, it is valuable to monitor genetic drift, coinfection with different SIV subtypes on pig farms and emerging new reassortants of SIVs (Simon et al. 2014; Rajao et al. 2017). Thus, isolation, subtyping and gene sequencing of field strains are required. However, virological tests do not always detect field cases as nasal shedding of virus occurs for a limited period of time (Van Reeth et al. 2003; Hemmink et al. 2016), resulting in many affected pigs returning a virus-negative outcome. Furthermore, it is often difficult to culture SIVs and therefore subtype them when the viral load in samples is low. For example, Lopez-Robles et al. (2014) reported that even when clinical signs were present in 22 of 25 pigs that were positive for viral RNA, only isolates from 6 affected pigs were able to be subtyped by RT-PCR.

It is recommended that risk-based surveillance strategies are implemented to improve the efficiency of SIV surveillance. Risk-based surveillance is designed to detect pathogens or infections in the most likely places, herds or individuals, and thus can improve sensitivity of the surveillance system leading to more efficient use of resources and time (East et al. 2013). For example, more samples should be collected from pigs with suspicious clinical signs or a high risk of exposure to SIVs. Riskbased surveillance relies on knowledge about the diseases' clinical signs, epidemiological characteristics, including the determinants for its spread and transmission (Stark et al. 2006; Oidtmann et al. 2013). Some studies have highlighted the advantages of risk-based surveillance for SI. For example, Li et al. (2020c) explored movement network of live pigs via live pig markets in south China, and the authors identified key areas that would have higher risk of having pathogens through the trading network. In addition, Ding et al. (2021) used existing SI surveillance data to develop machine learning models to predict the risks of human/avian influenza infection in pigs in different counties of south China.
Surveillance for influenza A viruses, including surveillance for SI, is in place in many countries (Kaden et al. 2008; Simon et al. 2014; Vincent et al. 2014; Kaplan et al. 2015). However, there is still room for improvement of SIV surveillance. Firstly, SI surveillance in key areas is insufficient. The surveillance capacity varies between countries, with many undeveloped countries having limited resources hindering their surveillance capacity. Secondly, the existing surveillance programs have not generated sufficient knowledge on the epidemiological features of SIV in different ecosystems. Thirdly, although passive surveillance is common in many countries, well-designed active surveillance is still rare. Passive surveillance may introduce bias in evaluating the presence and distribution of SIVs. Lastly, while more reassortants have been confirmed and compared by phylogenetic analysis, the relevant risk factors for continued circulation and persistent infection remain unclear (Trevennec et al. 2011; Vincent et al. 2014; Nelson et al. 2015b).

\section{Conclusions}

Swine influenza can result in a significant economic loss for the pig industry and potentially lead to pandemic influenza in humans. Co-circulation of different SIV strains in pig farms can facilitate gene reassortment between strains, resulting in the production of new circulating strains in pigs and strains with pandemic potential. Certain husbandry and management practices and poor biosecurity on pig farms are risk factors for SIV infection in pig farms. Although reliable diagnostic tests for the disease are available, and many studies are focusing on monitoring the gene evolution of swine influenza viruses, disease control in pig farms is challenging. Close contact between pigs and workers in the pig industry offer opportunities for zoonotic transmission of swine influenza virus. To control the potential of swinesource flu pandemics developing in humans is a need for controlling swine influenza in pig farms.

\section{Abbreviations \\ ADG: Average Daily Growth; cDNA: Complementary DNA; Cl: Confidence Interval; ECEs: Embryonated Chicken Eggs; ELISA: Enzyme-Linked Immunosorbent Assay; FCE: Feed Conversion Efficiency; HA: Hemagglutinin; HI test : Hemagglutination Inhibition Test; HPAl: Highly Pathogenic Avian Influenza; MDA : Maternally Derived Antibody; MDCK: The Madin-Darby Canine Kidney; Mhp: Mycoplasma hyopneumoniae; NA: Neuraminidase; NP: Nucleoprotein; OR : Odds Ratio; RT-PCR : Reverse Transcription- Polymerase Chain Reaction Test; RT-qPCR: Quantitative Reverse Transcription PCR; SI: Swine Influenza; SIV: Swine Influenza Virus; SNA : Social Network Analysis; UK: The United Kingdom; USA: The United States Of America; VI: Virus Isolation}

\section{Acknowledgements}

Not applicable. 


\section{Authors' contributions}

Yin Li drafted the manuscript. lan Robertson supervised the review and revised the manuscript. Both authors read and approved the final manuscript.

\section{Funding}

This study was partially funded by a MIPS Strategic Scholarship from Murdoch University.

\section{Availability of data and materials}

Not Applicable.

\section{Declarations}

\section{Ethics approval and consent to participate}

Not Applicable.

\section{Consent for publication}

Not applicable.

\section{Competing interests}

This study was funded by MIPS Strategic Scholarship from Murdoch University. The funder has no impact on the design of the study and the interpretation of the results. Author lan Robertson was not involved in the journal's review of, or decisions related to this manuscript. The authors declare that they have no competing interests.

\section{Author details \\ ${ }^{1}$ School of Veterinary Medicine, Murdoch University, Perth, WA, Australia. ${ }^{2}$ Commonwealth Scientific and Industrial Research Organisation, St. Lucia, QLD, Australia. ${ }^{3}$ College of Veterinary Medicine, Huazhong Agricultural University, Wuhan 430070, China. ${ }^{4}$ Hubei International Scientific and Technological Cooperation Base of Veterinary Epidemiology, Huazhong Agricultural University, Wuhan 430070, China.}

Received: 5 July 2021 Accepted: 7 September 2021

\section{Published online: 28 September 2021}

\section{References}

Abe, H., J. Mine, S. Parchariyanon, N. Takemae, P. Boonpornprasert, N. Ubonyaem, P. Patcharasinghawut, B. Nuansrichay, T. Tanikawa, R. Tsunekuni, and T. Saito. 2015. Co-infection of influenza a viruses of swine contributes to effective shuffling of gene segments in a naturally reared pig. Virology 484: 203-212 https://doi.org/10.1016/j.virol.2015.06.002.

Abente, E.J., P.C. Gauger, R.R. Walia, D.S. Rajao, J.Q. Zhang, K.M. Harmon, M.L. Killian, and A.L. Vincent. 2017. Detection and characterization of an H4N6 avian-lineage influenza a virus in pigs in the Midwestern United States. Virology 511: 56-65. https://doi.org/10.1016/j.virol.2017.08.021.

Allerson, M., J. Deen, S.E. Detmer, M.R. Gramer, H.S. Joo, A. Romagosa, and M. Torremorell. 2013a. The impact of maternally derived immunity on influenza a virus transmission in neonatal pig populations. Vaccine 31: 500-505.

Allerson, M.W., C.J. Cardona, and M. Torremorell. 2013b. Indirect transmission of influenza a virus between pig populations under two different biosecurity settings. PLoS One 8: e67293.

Almeida, H.M., G.Y. Storino, D.A. Pereira, I.R. Gatto, L.A. Mathias, H.J. Montassier, and L.G. de Oliveira. 2017. A cross-sectional study of swine influenza in intensive and extensive farms in the northeastern region of the state of Sao Paulo. Brazil. Trop. Anim. Health Prod. 49: 25-30.

Anderson, T.K., Macken, C.A., Lewis, N.S., Scheuermann, R.H., Van Reeth, K., Brown, I.H., Swenson, S.L., Simon, G., Saito, T., Berhane, Y., Ciacci-Zanella, J., Pereda, A. Davis, C.T., Donis, R.O., Webby, R.J., Vincent, A.L., 2016. A Phylogeny-Based Global Nomenclature System and Automated Annotation Tool for $\mathrm{H} 1$ Hemagglutinin Genes from Swine Influenza A Viruses. mSphere 1.

Baudon, E., D.K.W. Chu, D.D. Tung, P. Thi Nga, H. Vu Mai Phuong, N. Le Khanh Hang, L.T. Thanh, N.T. Thuy, N.C. Khanh, L.Q. Mai, N.V. Khong, B.J. Cowling, M. Peyre, and M. Peiris. 2018. Swine influenza viruses in northern Vietnam in 2013-2014. Emerg Microbes Infect 7: 123.

Baudon, E., M. Peyre, M. Peiris, and B.J. Cowling. 2017. Epidemiological features of influenza circulation in swine populations: A systematic review and metaanalysis. PLoS One 12: e0179044.
Baudon, E., M. Peyre, D.D. Tung, P. Thi Nga, N.V. Khong, B.J. Cowling, and M. Peiris. 2020. Surveillance of swine influenza viruses in sentinel familial farms in hung yen province in northern Vietnam in 2013-2014. Zoonoses and Public Health 67: 213-221.

Beato, M.S., L. Tassoni, A. Milani, A. Salviato, G. Di Martino, M. Mion, L. Bonfanti, I. Monne, S.J. Watson, and A. Fusaro. 2016. Circulation of multiple genotypes of H1N2 viruses in a swine farm in Italy over a two-month period. Veterinary Microbiology 195: 25-29.

Beaudoin, A., S. Johnson, P. Davies, J. Bender, and M. Gramer. 2012 Characterization of influenza a outbreaks in Minnesota swine herds and measures taken to reduce the risk of zoonotic transmission. Zoonoses and Public Health 59: 96-106.

Benton, D.J., S.A. Wharton, S.R. Martin, and J.W. McCauley. 2017. Role of neuraminidase in influenza a(H7N9) virus receptor binding. Journal of Virology 91.

Botner, A., and G.J. Belsham. 2012. Virus survival in slurry: Analysis of the stability of foot-and-mouth disease, classical swine fever, bovine viral diarrhoea and swine influenza viruses. Veterinary Microbiology 157 (1-2): 41-49. https://doi. org/10.1016/j.vetmic.2011.12.010.

Bowman, A.S., S.W. Nelson, J.L. Edwards, C.C. Hofer, J.M. Nolting, I.C. Davis, and R. D. Slemons. 2013. Comparative effectiveness of isolation techniques for contemporary influenza a virus strains circulating in exhibition swine. Journal of Veterinary Diagnostic Investigation 25: 82-90.

Bowman, A.S., S.W. Nelson, S.L. Page, J.M. Nolting, M.L. Killian, S. Sreevatsan, and R.D. Slemons. 2014a. Swine-to-human transmission of influenza a(H3N2) virus at agricultural fairs, Ohio, USA, 2012. Emerging Infectious Diseases 20: 1472-1480.

Bowman, A.S., J.D. Workman, J.M. Nolting, S.W. Nelson, and R.D. Slemons. 2014 b. Exploration of risk factors contributing to the presence of influenza a virus in swine at agricultural fairs. Emerging microbes \& infections 3: e5.

Brown, I.H. 2000. The epidemiology and evolution of influenza viruses in pigs. Veterinary Microbiology 74 (1-2): 29-46. https://doi.org/10.1016/S0378-113 5(00)00164-4.

Bui, C.M., A.A. Chughtai, D.C. Adam, and C.R. MacIntyre. 2017. An overview of the epidemiology and emergence of influenza a infection in humans over time. Arch Public Health 75: 15.

Cador, C., S. Herve, M. Andraud, S. Gorin, F. Paboeuf, N. Barbier, S. Queguiner, C Deblanc, G. Simon, and N. Rose. 2016. Maternally-derived antibodies do not prevent transmission of swine influenza a virus between pigs. Veterinary Research 47: 86.

Chamba Pardo, F.O., S. Wayne, M.R. Culhane, A. Perez, M. Allerson, and M. Torremorell. 2019. Effect of strain-specific maternally-derived antibodies on influenza a virus infection dynamics in nursery pigs. PLoS One 14: e0210700.

Chen, J., X. Fu, Y. Chen, S. He, Y. Zheng, Z. Cao, W. Yu, H. Zhou, S. Su, and G. Zhang. 2014a. Identification of four genotypes of H3N2 swine influenza virus in pigs from southern China. Archives of Virology 159: 2705-2709.

Chen, Y., J. Zhang, C. Qiao, J. Wang, H. Yang, and H. Chen. 2014b. Identification of a linear epitope on the haemagglutinin protein of pandemic a/H1N1 2009 influenza virus using monoclonal antibodies. Archives of Virology 159: 1413-1419.

Chen, Y., J. Zhang, C. Qiao, H. Yang, Y. Zhang, X. Xin, and H. Chen. 2013. Cocirculation of pandemic 2009 H1N1, classical swine H1N1 and avian-like swine H1N1 influenza viruses in pigs in China. Infection, Genetics and Evolution 13: 331-338

Chiapponi, C. I. Zanni, C. Garbarino, G. Barigazzi, and E. Foni. 2010. Comparison of the usefulness of the CACO-2 cell line with standard substrates for isolation of swine influenza a viruses. Journal of Virological Methods 163: 162-165.

Choi, Y.K., S.M. Goyal, and H.S. Joo. 2004. Evaluation of transmission of swine influenza type a subtype H1N2 virus in seropositive pigs. American Journal of Veterinary Research 65: 303-306.

Clavijo, A., D.B. Tresnan, R. Jolie, and E.M. Zhou. 2002. Comparison of embryonated chicken eggs with MDCK cell culture for the isolation of swine influenza virus. Canadian Journal of Veterinary Research 66: 117-121.

Corzo, C.A., M. Culhane, K. Juleen, E. Stigger-Rosser, M.F. Ducatez, R.J. Webby, and J.F. Lowe. 2013a. Active surveillance for influenza a virus among swine, midwestern United States, 2009-2011. Emerging Infectious Diseases 19: 954-960.

Corzo, C.A., A. Romagosa, S.A. Dee, M.R. Gramer, R.B. Morrison, and M. Torremorell. 2013b. Relationship between airborne detection of influenza a virus and the number of infected pigs. Veterinary Journal 196: 171-175.

Couacy-Hymann, E., V.A. Kouakou, G.L. Aplogan, F. Awoume, C.K. Kouakou, L. Kakpo, B.R. Sharp, L. McClenaghan, P. McKenzie, R.G. Webster, R.J. Webby, and M.F. Ducatez. 2012. Surveillance for influenza viruses in poultry and swine, West Africa, 2006-2008. Emerging Infectious Diseases 18: 1446-1452. 
Cui, J.A., and F.Y. Chen. 2017. Effects of isolation and slaughter strategies in different species on emerging zoonoses. Mathematical Biosciences and Engineering 14 (5/6): 1119-1140. https://doi.org/10.3934/mbe.2017058.

David, E.S., David, L.S., Leslie, D.S., 2020. Influenza. In: David, E.S., Martine, B. Catherine, M.L., Larry, R.M., Venugopal, N., David, L.S. (Eds.), Diseases of poultry. John Wiley \& Sons, Inc., NJ, USA, 210-256.

Deblanc, C., F. Robert, T. Pinard, S. Gorin, S. Queguiner, A.V. Gautier-Bouchardon, S. Ferre, J.M. Garraud, R. Cariolet, M. Brack, and G. Simon. 2013. Pre-infection of pigs with mycoplasma hyopneumoniae induces oxidative stress that influences outcomes of a subsequent infection with a swine influenza virus of H1N1 subtype. Veterinary Microbiology 162: 643-651.

Detmer, S., M. Gramer, S. Goyal, M. Torremorell, and J. Torrison. 2013. Diagnostics and surveillance for swine influenza. Current Topics in Microbiology and Immunology 370: 85-112

Ding, F., Y. Li, B. Huang, J. Edwards, C. Cai, G. Zhang, D. Jiang, Q. Wang, and I.D. Robertson. 2021. Infection and risk factors of human and avian influenza in pigs in South China. Preventive Veterinary Medicine 190: 105317

Dorjee, S., C.W. Revie, Z. Poljak, W.B. McNab, J.T. McClure, and J. Sanchez. 2016. One-health simulation modelling: Assessment of control strategies against the spread of influenza between swine and human populations using NAAD SM. Transboundary and Emerging Diseases 63: e229-e244.

East, I.J., R.M. Wicks, P.A. Martin, E.S. Sergeant, L.A. Randall, and M.G. Garner. 2013. Use of a multi-criteria analysis framework to inform the design of risk based general surveillance systems for animal disease in Australia. Preventive Veterinary Medicine 112: 230-247.

Er, C., B. Lium, S. Tavornpanich, P.O. Hofmo, H. Forberg, A.G. Hauge, C.A. Grontvedt, T. Framstad, and E. Brun. 2014. Adverse effects of influenza a(H1N1)pdm09 virus infection on growth performance of Norwegian pigs - a longitudinal study at a boar testing station. BMC Veterinary Research 10: 284.

Er, C., E. Skjerve, E. Brun, T. Framstad, and B. Lium. 2016a. Occurrence and spread of influenza a(H1N1)pdm09 virus infection in Norwegian pig herds based on active serosurveillance from 2010 to 2014. Epidemiology and Infection 144: 3148-3165.

Er, C., E. Skjerve, E. Brun, P.O. Hofmo, T. Framstad, and B. Lium. 2016b. Production impact of influenza a(H1N1)pdm09 virus infection on fattening pigs in Norway. Journal of Animal Science 94 (2): 751-759. https:/doi.org/10.2527/jas.2015-9251.

European Union, 2021. Major knowledge gaps yet to be filled to fight animal influenza. Horizon 2020.

Fablet, C., C. Marois-Crehan, G. Simon, B. Grasland, A. Jestin, M. Kobisch, F. Madec, and N. Rose. 2012. Infectious agents associated with respiratory diseases in 125 farrow-to-finish pig herds: A cross-sectional study. Veterinary Microbiology 157: $152-163$.

Fablet, C., G. Simon, V. Dorenlor, F. Eono, E. Eveno, S. Gorin, S. Queguiner, F. Madec, and N. Rose. 2013. Different herd level factors associated with H1N1 or H1N2 influenza virus infections in fattening pigs. Preventive Veterinary Medicine 112: 257-265.

Fang, L.Q., C.X. Cao, G.S. Chen, F.M. Lei, Y.L. Liu, C.Y. Li, H. Yang, X.N. Han, L. Yan, X.W. Li, and W.C. Cao. 2005. Studies on the spatial distribution and environmental factors of highly pathogenic avian influenza in mainland China, using geographic information system technology. Zhonghua Liu Xing Bing Xue Za Zhi 26: 839-842.

Ferenczi, M., C. Beckmann, S. Warner, R. Loyn, K. O'Riley, X. Wang, and M. Klaassen. 2016. Avian influenza infection dynamics under variable climatic conditions, viral prevalence is rainfall driven in waterfowl from temperate, south-East Australia. Veterinary Research 47: 23.

Filippitzi, M.E., A.B. Kruse, M. Postma, S. Sarrazin, D. Maes, L. Alban, L.R. Nielsen, and J. Dewulf. 2018. Review of transmission routes of 24 infectious diseases preventable by biosecurity measures and comparison of the implementation of these measures in pig herds in six European countries. Transboundary and Emerging Diseases 65: 381-398.

Fraaij, P.L., Wildschut, E.D., Houmes, R.J., Swaan, C.M., Hoebe, C.J., de Jonge, H.C., Tolsma, P., de Kleer, I., Pas, S.D., Oude Munnink, B.B., Phan, M.V., Bestebroer, T. M., Roosenhoff, R.S., van Kampen, J.J., Cotten, M., Beerens, N., Fouchier, R.A., van den Kerkhof, J.H., Timen, A., Koopmans, M.P., 2016. Severe acute respiratory infection caused by swine influenza virus in a child necessitating extracorporeal membrane oxygenation (ECMO), the Netherlands, October 2016a. Euro Surveillance 21.

Garten, R.J., C.T. Davis, C.A. Russell, B. Shu, S. Lindstrom, A. Balish, W.M. Sessions, X. Xu, E. Skepner, V. Deyde, M. Okomo-Adhiambo, L. Gubareva, J. Barnes, C.B. Smith, S.L. Emery, M.J. Hillman, P. Rivailler, J. Smagala, M. de Graaf, D.F. Burke, R.A. Fouchier, C. Pappas, C.M. Alpuche-Aranda, H. Lopez-Gatell, H. Olivera, I.
Lopez, C.A. Myers, D. Faix, P.J. Blair, C. Yu, K.M. Keene, P.D. Dotson Jr., D. Boxrud, A.R. Sambol, S.H. Abid, K. St George, T. Bannerman, A.L. Moore, D.J. Stringer, P. Blevins, G.J. Demmler-Harrison, M. Ginsberg, P. Kriner, S. Waterman, S. Smole, H.F. Guevara, E.A. Belongia, P.A. Clark, S.T. Beatrice, R. Donis, J. Katz, L. Finelli, C.B. Bridges, M. Shaw, D.B. Jernigan, T.M. Uyeki, D.J. Smith, A.I. Klimov, and N.J. Cox. 2009. Antigenic and genetic characteristics of swine-origin 2009 a(H1 N1) influenza viruses circulating in humans. Science 325: 197-201.

Gerber, P.F., L. Dawson, B. Strugnell, R. Burgess, H. Brown, and T. Opriessnig. 2017. Using oral fluids samples for indirect influenza a virus surveillance in farmed UK pigs. Vet Med Sci 3: 3-12.

Gomaa, M.R., A. Kandeil, R. El-Shesheny, M.M. Shehata, P.P. McKenzie, R.J. Webby, M.A. Ali, and G. Kayali. 2018. Evidence of infection with avian, human, and swine influenza viruses in pigs in Cairo. Egypt. Arch. Virol. 163: 359-364.

Gonzalez-Reiche, A.S., A.L. Ramirez, M.L. Muller, D. Orellana, S.M. Sosa, P. Ola, J. Paniagua, L. Ortiz, J. Hernandez, C. Cordon-Rosales, and D.R. Perez. 2017. Origin, distribution, and potential risk factors associated with influenza a virus in swine in two production systems in Guatemala. Influenza and Other Respiratory Viruses 11: 182-192.

Goodell, C.K., J. Prickett, A. Kittawornrat, J. Johnson, J. Zhang, C. Wang, and J.J. Zimmerman. 2016. Evaluation of screening assays for the detection of influenza a virus serum antibodies in swine. Transboundary and Emerging Diseases 63: 24-35.

Gregory, V., W. Lim, K. Cameron, M. Bennett, S. Marozin, A. Klimov, H. Hall, N. Cox, A. Hay, and Y.P. Lin. 2001. Infection of a child in Hong Kong by an influenza a $\mathrm{H} 3 \mathrm{~N} 2$ virus closely related to viruses circulating in European pigs. The Journal of General Virology 82: 1397-1406.

Grontvedt, C.A., C. Er, B. Gjerset, A.G. Hauge, E. Brun, A. Jorgensen, B. Lium, and T. Framstad. 2013. Influenza a(H1N1)pdm09 virus infection in Norwegian swine herds 2009/10: The risk of human to swine transmission. Preventive Veterinary Medicine 110: 429-434.

Gumbert, S., S. Froehlich, A. Rieger, J. Stadler, M. Ritzmann, and S. Zoels. 2020. Reproductive performance of pandemic influenza a virus infected sow herds before and after implementation of a vaccine against the influenza a (H1N1)pdm09 virus. Porcine Health Manag. 6: 9.

Haas, B., R. Ahl, R. Bohm, and D. Strauch. 1995. Inactivation of viruses in liquid manure. Revue scientifique et technique (International Office of Epizootics) 14: 435-445.

Hause, B.M., E.A. Collin, R. Liu, B. Huang, Z. Sheng, W. Lu, D. Wang, E.A. Nelson, and F. Li. 2014. Characterization of a novel influenza virus in cattle and swine: Proposal for a new genus in the Orthomyxoviridae family. MBio 5 (2): e00031e00014. https://doi.org/10.1128/mBio.00031-14

Hemmink, J.D., S.B. Morgan, M. Aramouni, H. Everett, F.J. Salguero, L. Canini, E. Porter, M. Chase-Topping, K. Beck, R.M. Loughlin, B.V. Carr, I.H. Brown, M. Bailey, M. Woolhouse, S.M. Brookes, B. Charleston, and E. Tchilian. 2016. Distinct immune responses and virus shedding in pigs following aerosol, intra-nasal and contact infection with pandemic swine influenza a virus, $\mathrm{a}(\mathrm{H} 1 \mathrm{~N} 1) 09$. Veterinary Research 47: 103.

Henritzi, D., P.P. Petric, N.S. Lewis, A. Graaf, A. Pessia, E. Starick, A. Breithaupt, G. Strebelow, C. Luttermann, L.M.K. Parker, C. Schroder, B. Hammerschmidt, G. Herrler, E.G. Beilage, D. Stadlbauer, V. Simon, F. Krammer, S. Wacheck, S. Pesch, M. Schwemmle, M. Beer, and T.C. Harder. 2020. Surveillance of European domestic pig populations identifies an emerging reservoir of potentially zoonotic swine influenza a viruses. Cell Host \& Microbe 28 (614627): e616.

Henritzi, D., N. Zhao, E. Starick, G. Simon, J.S. Krog, L.E. Larsen, S.M. Reid, I.H. Brown, C. Chiapponi, E. Foni, S. Wacheck, P. Schmid, M. Beer, B. Hoffmann, and T.C. Harder. 2016. Rapid detection and subtyping of European swine influenza viruses in porcine clinical samples by haemagglutinin- and neuraminidase-specific tetra- and triplex real-time RT-PCRs. Influenza and Other Respiratory Viruses 10: 504-517.

Inoue, E., X.F. Wang, Y. Osawa, and K. Okazaki. 2010. Full genomic amplification and subtyping of influenza a virus using a single set of universal primers. Microbiology and Immunology 54: 129-134.

Ito, T., J.N. Couceiro, S. Kelm, L.G. Baum, S. Krauss, M.R. Castrucci, I. Donatelli, H. Kida, J.C. Paulson, R.G. Webster, and Y. Kawaoka. 1998. Molecular basis for the generation in pigs of influenza a viruses with pandemic potential. Journal of Virology 72: 7367-7373.

Jeong, E.K., J.E. Bae, and I.S. Kim. 2010. Inactivation of influenza a virus H1N1 by disinfection process. American Journal of Infection Control 38: 354-360. 
Kaden, V., E. Lange, E. Starick, W. Bruer, W. Krakowski, and M. Klopries. 2008. Epidemiological survey of swine influenza a virus in selected wild boar populations in Germany. Veterinary Microbiology 131: 123-132.

Kaplan, B.S., J. DeBeauchamp, E. Stigger-Rosser, J. Franks, J.C. Crumpton, J. Turner, D. Darnell, T. Jeevan, G. Kayali, A. Harding, R.J. Webby, and J.F. Lowe. 2015. Influenza virus surveillance in coordinated swine production systems, United States. Emerging Infectious Diseases 21: 1834-1836.

Karasin, A.I., I.H. Brown, S. Carman, and C.W. Olsen. 2000. Isolation and characterization of H4N6 avian influenza viruses from pigs with pneumonia in Canada. Journal of Virology 74: 9322-9327.

Killian, M.L., S.L. Swenson, A.L. Vincent, J.G. Landgraf, B. Shu, S. Lindstrom, X. Xu, A. Klimov, Y. Zhang, and A.S. Bowman. 2013. Simultaneous infection of pigs and people with triple-reassortant swine influenza virus H1N1 at a U.S. county fair. Zoonoses and Public Health 60: 196-201.

Kong, W., F. Wang, B. Dong, C. Ou, D. Meng, J. Liu, and Z.C. Fan. 2015. Novel reassortant influenza viruses between pandemic (H1N1) 2009 and other influenza viruses pose a risk to public health. Microbial Pathogenesis 89: 62-72.

Kothalawala, H., M.J. Toussaint, and E. Gruys. 2006. An overview of swine influenza. The Veterinary Quarterly 28 (2): 45-53. https://doi.org/10.1080/01 652176.2006.9695207.

Kyriakis, C.S., N. Rose, E. Foni, J. Maldonado, W.L. Loeffen, F. Madec, G. Simon, and K. Van Reeth. 2013. Influenza a virus infection dynamics in swine farms in Belgium, France, Italy and Spain, 2006-2008. Veterinary Microbiology 162: 543550.

Lantos, P.M., K. Hoffman, M. Hohle, B. Anderson, and G.C. Gray. 2016. Are people living near modern swine production facilities at increased risk of influenza virus infection? Clinical Infectious Diseases 63: 1558-1563.

Lewis, N.S., C.A. Russell, P. Langat, T.K. Anderson, K. Berger, F. Bielejec, D.F. Burke, G. Dudas, J.M. Fonville, R.A. Fouchier, P. Kellam, B.F. Koel, P. Lemey, T. Nguyen, B. Nuansrichy, J.M. Peiris, T. Saito, G. Simon, E. Skepner, N. Takemae, E. Consortium, R.J. Webby, K. Van Reeth, S.M. Brookes, L. Larsen, S.J. Watson, I. H. Brown, and A.L. Vincent. 2016. The global antigenic diversity of swine influenza a viruses. Elife 5: e12217.

Li, S., Y. Zhou, Y. Zhao, W. Li, W. Song, and Z. Miao. 2015. Avian influenza H9N2 seroprevalence among pig population and pig farm staff in Shandong. China. Virol J. 12: 34

Li, Y., J. Edwards, B. Huang, C. Shen, C. Cai, Y. Wang, G. Zhang, and I. Robertson. 2020a. Risk of zoonotic transmission of swine influenza at the human-pig interface in Guangdong Province. China: Zoonoses Public Health.

Li, Y., J. Edwards, B.X. Huang, C.J. Shen, C. Cai, Y.M. Wang, G.H. Zhang, and I. Robertson. 2020b. Risk of zoonotic transmission of swine influenza at the human-pig interface in Guangdong Province. China: Zoonoses Public Health.

Li, Y., J. Edwards, Y. Wang, G. Zhang, C. Cai, M. Zhao, B. Huang, and I.D. Robertson. 2019. Prevalence, distribution and risk factors of farmer reported swine influenza infection in Guangdong Province. China. Prev. Vet. Med. 167 $1-8$.

Li, Y., B. Huang, C. Shen, C. Cai, Y. Wang, J. Edwards, G. Zhang, and I.D. Robertson. 2020c. Pig trade networks through live pig markets in Guangdong Province. China. Transbound. Emerg. Dis. 67 (3): 1315-1329. https://doi.org/10.1111/ tbed.13472.

Lin, S.Y., Y.H. Chen, P.L. Lu, Y.M. Tsai, and T.C. Chen. 2016. An underestimated coinfection: Swine influenza and pneumonia due to legionella pneumophila. The American Journal of the Medical Sciences 352: 314-316.

Liu, W., M.T. Wei, Y. Tong, F. Tang, L. Zhang, L. Fang, H. Yang, and W.C. Cao. 2011. Seroprevalence and genetic characteristics of five subtypes of influenza a viruses in the Chinese pig population: A pooled data analysis. Veterinary Journal 187: 200-206

Loeffen, W.L., G. Nodelijk, P.P. Heinen, L.A. van Leengoed, W.A. Hunneman, and J. $H$. Verheijden. 2003. Estimating the incidence of influenza-virus infections in Dutch weaned piglets using blood samples from a cross-sectional study. Veterinary Microbiology 91: 295-308.

Lombardi, M.E., B.S. Ladman, R.L. Alphin, and E.R. Benson. 2008. Inactivation of avian influenza virus using common detergents and chemicals. Avian Diseases 52: 118-123.

Lopez-Robles, G., M. Montalvo-Corral, A. Burgara-Estrella, and J. Hernandez. 2014 Serological and molecular prevalence of swine influenza virus on farms in northwestern Mexico. Veterinary Microbiology 172: 323-328.

Lopez-Robles, G., M. Montalvo-Corral, G. Caire-Juvera, G. Ayora-Talavera, and J. Hernandez. 2012. Seroprevalence and risk factors for swine influenza zoonotic transmission in swine workers from northwestern Mexico. Transboundary and Emerging Diseases 59: 183-188.
Luo, J., L. Ferguson, D.R. Smith, A.R. Woolums, W.B. Epperson, and X.F. Wan. 2017. Serological evidence for high prevalence of influenza $D$ viruses in cattle, Nebraska, United States, 2003-2004. Virology 501: 88-91. https://doi.org/10.1 016/j.virol.2016.11.004.

Ma, M., B.D. Anderson, T. Wang, Y. Chen, D. Zhang, G.C. Gray, and J. Lu. 2015. Serological evidence and risk factors for swine influenza infections among Chinese swine Workers in Guangdong Province. PLoS One 10: e0128479.

Mancera Gracia, J.C., D.S. Pearce, A. Masic, and M. Balasch. 2020. Influenza a virus in swine: Epidemiology, challenges and vaccination strategies. Front Vet Sci 7 : 647.

Mastin, A., P. Alarcon, D. Pfeiffer, J. Wood, S. Williamson, I. Brown, and B. Wieland. 2011. Prevalence and risk factors for swine influenza virus infection in the English pig population. PLoS currents 3: RRN1209.

Mehle, A. 2014. Unusual influenza a viruses in bats. Viruses 6: 3438-3449.

Meseko, C., A. Globig, J. ljomanta, T. Joannis, C. Nwosuh, D. Shamaki, T. Harder, D. Hoffman, A. Pohlmann, M. Beer, T. Mettenleiter, and E. Starick. 2018. Evidence of exposure of domestic pigs to highly pathogenic avian influenza H5N1 in Nigeria. Scientific Reports 8: 5900.

Mine, J., H. Abe, S. Parchariyanon, P. Boonpornprasert, N. Ubonyaem, B. Nuansrichay, N. Takemae, T. Tanikawa, R. Tsunekuni, Y. Uchida, and T. Saito. 2019. Genetic and antigenic dynamics of influenza a viruses of swine on pig farms in Thailand. Archives of Virology 164: 457-472.

Nasamran, C., T. Janetanakit, S. Chiyawong, S. Boonyapisitsopa, N. Bunpapong, D. Prakairungnamthip, A. Thontiravong, and A. Amonsin. 2020. Persistence of pdm2009-H1N1 internal genes of swine influenza in pigs. Thailand. Sci. Rep. 10: 19847.

Nava, G.M., R. Merino, R. Jarquin, N. Ledesma, I. Sanchez-Betancourt, E. Lucio, E. Martinez, and M. Escorcia. 2013. A rapid test for avian influenza detects swine influenza virus. The Veterinary Record 173: 424

Nelson, M.I., J. Stratton, M.L. Killian, A. Janas-Martindale, and A.L. Vincent. $2015 \mathrm{a}$. Continual reintroduction of human pandemic H1N1 influenza a viruses into swine in the United States, 2009 to 2014. Journal of Virology 89: 6218-6226.

Nelson, M.I., C. Viboud, A.L. Vincent, M.R. Culhane, S.E. Detmer, D.E. Wentworth, A. Rambaut, M.A. Suchard, E.C. Holmes, and P. Lemey. 2015b. Global migration of influenza a viruses in swine. Nature Communications 6 (1): 6696. https:// doi.org/10.1038/ncomms7696.

Nelson, M.I., and A.L. Vincent. 2015. Reverse zoonosis of influenza to swine: New perspectives on the human-animal interface. Trends in Microbiology 23: 142-153.

Ninomiya, A., A. Takada, K. Okazaki, K.F. Shortridge, and H. Kida. 2002. Seroepidemiological evidence of avian $\mathrm{H} 4, \mathrm{H} 5$, and $\mathrm{H} 9$ influenza a virus transmission to pigs in southeastern China. Veterinary Microbiology 88 (2): 107-114. https://doi.org/10.1016/S0378-1135(02)00105-0.

Nonthabenjawan, N., S. Chanvatik, S. Chaiyawong, W. Jairak, S. Boonyapisusopha, R. Tuanudom, A. Thontiravong, N. Bunpapong, and A. Amonsin. 2015. Genetic diversity of swine influenza viruses in Thai swine farms, 2011-2014. Virus Genes 50 (2): 221-230. https://doi.org/10.1007/s11262-014-1153-X.

Oidtmann, B., E. Peeler, T. Lyngstad, E. Brun, B.B. Jensen, and K.D.C. Stark. 2013. Risk-based methods for fish and terrestrial animal disease surveillance. Preventive Veterinary Medicine 112: 13-26.

Osterhaus, A.D., G.F. Rimmelzwaan, B.E. Martina, T.M. Bestebroer, and R.A. Fouchier. 2000. Influenza B virus in seals. Science 288: 1051-1053.

Ovsyannikova, I.G., S.J. White, R.A. Albrecht, A. Garcia-Sastre, and G.A. Poland. 2014. Turkey versus guinea pig red blood cells: Hemagglutination differences alter hemagglutination inhibition responses against influenza a/H1N1. Viral Immunology 27: 174-178.

Ozawa, M., A. Matsuu, K. Yonezawa, M. Igarashi, K. Okuya, T. Kawabata, K. Ito, K. Tsukiyama-Kohara, A. Taneno, and E. Deguchi. 2015. Efficient isolation of swine influenza viruses by age-targeted specimen collection. Journal of Clinical Microbiology 53: 1331-1338.

Panyasing, Y., C.K. Goodell, C. Wang, A. Kittawornrat, J.R. Prickett, K.J. Schwartz, A. Ballagi, S. Lizano, and J.J. Zimmerman. 2014. Detection of influenza a virus nucleoprotein antibodies in oral fluid specimens from pigs infected under experimental conditions using a blocking ELISA. Transboundary and Emerging Diseases 61: 177-184.

Pasma, T. 2008. Spatial epidemiology of an H3N2 swine influenza outbreak. The Canadian Veterinary Journal 49: 167-176.

Pospisil, Z., P. Lany, B. Tumova, J. Buchta, D. Zendulkova, and P. Cihal. 2001. Swine influenza surveillance and the impact of human influenza epidemics on pig herds in the Czech Republic. Acta Veterinaria Brno 70: 327-332.

Qiao, C., L. Liu, H. Yang, Y. Chen, H. Xu, and H. Chen. 2014. Novel triple reassortant $\mathrm{H} 1 \mathrm{~N} 2$ influenza viruses bearing six internal genes of the 
pandemic 2009/H1N1 influenza virus were detected in pigs in China. Journal of Clinical Virology 61: 529-534.

Rajao, D.S., R.R. Walia, B. Campbell, P.C. Gauger, A. Janas-Martindale, M.L. Killian, and A.L. Vincent. 2017. Reassortment between swine H3N2 and 2009 pandemic H1N1 in the United States resulted in influenza a viruses with diverse genetic constellations with variable virulence in pigs. Journal of Virology 91 (4): e01763. https://doi.org/10.1128/JVI.01763-16.

Rech, R.R., D. Gava, M.C. Silva, L.T. Fernandes, V. Haach, J.R. Ciacci-Zanella, and R. Schaefer. 2018. Porcine respiratory disease complex after the introduction of H1N1/2009 influenza virus in Brazil. Zoonoses and Public Health 65: e155-e161.

Reeth, K.V., Brown, I.H., Olsen, C.W., 2012. Influenza virus. In: Zimmerman, J.J., Karriker, L.a., Ramirez, a., Schwartz, K.J., Stevenson, G.W. (Eds.), diseases of swine. John Wiley \& Sons, Inc., West Sussex, PO19 8SQ, UK, 557-571.

Richt, J.A., K.M. Lager, D.F. Clouser, E. Spackman, D.L. Suarez, and K.J. Yoon. 2004. Real-time reverse transcription-polymerase chain reaction assays for the detection and differentiation of north American swine influenza viruses. Journal of Veterinary Diagnostic Investigation 16: 367-373.

Robertson, I.D. 2020. Disease control, prevention and on-farm biosecurity: The role of veterinary epidemiology. Engineering 6: 20-25.

Rose, N., S. Herve, E. Eveno, N. Barbier, F. Eono, V. Dorenlor, M. Andraud, C. Camsusou, F. Madec, and G. Simon. 2013. Dynamics of influenza a virus infections in permanently infected pig farms: Evidence of recurrent infections, circulation of several swine influenza viruses and reassortment events. Veterinary Research 44: 72.

Rovida, F., Piralla, A., Marzani, F.C., Moreno, A., Campanini, G., Mojoli, F., Pozzi, M., Girello, A., Chiapponi, C., Vezzoli, F., Prati, P., Percivalle, E., Pavan, A. Gramegna, M., lotti, G.A., Baldanti, F., 2017. Swine influenza A (H1N1) virus (SIV) infection requiring extracorporeal life support in an immunocompetent adult patient with indirect exposure to pigs, Italy, October 2016b. Euro Surveillance 22

Short, K.R., M. Richard, J.H. Verhagen, D. van Riel, E.J. Schrauwen, J.M. van den Brand, B. Manz, R. Bodewes, and S. Herfst. 2015. One health, multiple challenges: The inter-species transmission of influenza a virus. One Health 1: 1-13. https://doi.org/10.1016/j.onehlt.2015.03.001.

Si, Y., W.F. de Boer, and P. Gong. 2013. Different environmental drivers of highly pathogenic avian influenza H5N1 outbreaks in poultry and wild birds. PLoS One 8: e53362.

Simon-Grife, M., G.E. Martin-Valls, M.J. Vilar, I. Garcia-Bocanegra, M. Mora, M. Martin, E. Mateu, and J. Casal. 2011. Seroprevalence and risk factors of swine influenza in Spain. Veterinary Microbiology 149: 56-63.

Simon, G., L.E. Larsen, R. Durrwald, E. Foni, T. Harder, K. Van Reeth, I. MarkowskaDaniel, S.M. Reid, A. Dan, J. Maldonado, A. Huovilainen, C. Billinis, I. Davidson, M. Aguero, T. Vila, S. Herve, S.O. Breum, C. Chiapponi, K. Urbaniak, C.S. Kyriakis, I.H. Brown, and W. Loeffen. 2014. European surveillance network for influenza in pigs: Surveillance programs, diagnostic tools and swine influenza virus subtypes identified in 14 European countries from 2010 to 2013. PLoS One 9: e115815.

Song, X.H., H. Xiao, Y. Huang, G. Fu, B. Jiang, Y. Kitamura, W. Liu, D. Liu, and G.F. Gao. 2010. Serological surveillance of influenza a virus infection in swine populations in Fujian province, China: No evidence of naturally occurring H5N1 infection in pigs. Zoonoses and Public Health 57: 291-298.

Stark, K.D.C., G. Regula, J. Hernandez, L. Knopf, K. Fuchs, R.S. Morris, and P. Davies. 2006. Concepts for risk-based surveillance in the field of veterinary medicine and veterinary public health: Review of current approaches. BMC Health Services Research 6: 1-8.

Sun, H.L., J.T. Lin, Z.T. Liu, Y.N. Yu, M.H. Wu, S. Li, Y. Liu, Y.L. Feng, Y.Q. Wu, M.L. Li, P.R. Jiao, K.J. Luo, and M. Liao. 2019. Genetic, molecular, and pathogenic characterization of the H9N2 avian influenza viruses currently circulating in South China. Viruses 11: 1040.

Takemae, N., M. Harada, P.T. Nguyen, T. Nguyen, T.N. Nguyen, To, T.L., T.D. Nguyen, V.P. Pham, V.T. Le, H.T. Do, H.V. Vo, Q.V.T. Le, T.M. Tran, T.D. Nguyen, P.D. Thai, D.H. Nguyen, A.Q.T. Le, D.T. Nguyen, Y. Uchida, and T. Saito. 2017. Influenza a viruses of swine (IAV-S) in Vietnam from 2010 to 2015: Multiple introductions of a(H1N1)pdm09 viruses into the pig population and diversifying genetic constellations of enzootic IAV-S. Journal of Virology 91.

Takemae, N., P.T. Nguyen, V.T. Le, T.N. Nguyen, To, T.L., T.D. Nguyen, V.P. Pham, H. V. Vo, Q.V.T. Le, H.T. Do, D.T. Nguyen, Y. Uchida, and T. Saito. 2018. Appearance of reassortant European avian-origin $\mathrm{H} 1$ influenza a viruses of swine in Vietnam. Transboundary and Emerging Diseases 65: 1110-1116.

Takemae, N., S. Parchariyanon, R. Ruttanapumma, Y. Hiromoto, T. Hayashi, Y. Uchida, and T. Saito. 2011. Swine influenza virus infection in different age groups of pigs in farrow-to-finish farms in Thailand. Virology Journal 8: 537.
Takemae, N., Y. Shobugawa, P.T. Nguyen, T. Nguyen, T.N. Nguyen, To, T.L., P.D Thai, T.D. Nguyen, D.T. Nguyen, D.K. Nguyen, H.T. Do, T.Q. Le, P.T. Hua, H. Van Vo, D.H. Nguyen, Y. Uchida, R. Saito, and T. Saito. 2016. Effect of herd size on subclinical infection of swine in Vietnam with influenza a viruses. BMC Veterinary Research 12: 227.

Tang, J.W., N. Shetty, and T.T. Lam. 2010. Features of the new pandemic influenza a/H1N1/2009 virus: Virology, epidemiology, clinical and public health aspects. Current Opinion in Pulmonary Medicine 16: 235-241.

Trevennec, K., B.J. Cowling, M. Peyre, E. Baudon, G.P. Martineau, and F. Roger. 2011. Swine influenza surveillance in East and Southeast Asia: A systematic review. Animal Health Research Reviews 12 (2): 213-223. https://doi.org/10.101 7/S1466252311000181.

Trevennec, K., L. Leger, F. Lyazrhi, E. Baudon, C.Y. Cheung, F. Roger, M. Peiris, and J.M. Garcia. 2012. Transmission of pandemic influenza H1N1 (2009) in Vietnamese swine in 2009-2010. Influenza and Other Respiratory Viruses 6: 348-357.

Trombetta, C.M., C. Ulivieri, R.J. Cox, E.J. Remarque, C. Centi, D. Perini, G. Piccini, S. Rossi, S. Marchi, and E. Montomoli. 2018. Impact of erythrocyte species on assays for influenza serology. Journal of Preventive Medicine and Hygiene 59: E1-E7

van der Meer, F.J., K. Orsel, and H.W. Barkema. 2010. The new influenza a H1N1 virus: Balancing on the interface of humans and animals. The Canadian Veterinary Journal 51: 56-62.

Van Reeth, K., V. Gregory, A. Hay, and M. Pensaert. 2003. Protection against a European H1N2 swine influenza virus in pigs previously infected with H1N1 and/or H3N2 subtypes. Vaccine 21: 1375-1381.

Van Reeth, K., G. Labarque, and M. Pensaert. 2006. Serological profiles after consecutive experimental infections of pigs with European H1N1, H3N2, and H1N2 swine influenza viruses. Viral Immunology 19 (3): 373-382. https://doi. org/10.1089/vim.2006.19.373.

Vijaykrishna, D., G.J. Smith, O.G. Pybus, H. Zhu, S. Bhatt, L.L. Poon, S. Riley, J. Bahl, S.K. Ma, C.L. Cheung, R.A. Perera, H. Chen, K.F. Shortridge, R.J. Webby, R.G. Webster, Y. Guan, and J.S. Peiris. 2011. Long-term evolution and transmission dynamics of swine influenza a virus. Nature 473: 519-522.

Vincent, A., L. Awada, I. Brown, H. Chen, F. Claes, G. Dauphin, R. Donis, M. Culhane, K. Hamilton, N. Lewis, E. Mumford, T. Nguyen, S. Parchariyanon, J. Pasick, G. Pavade, A. Pereda, M. Peiris, T. Saito, S. Swenson, K. Van Reeth, R. Webby, F. Wong, and J. Ciacci-Zanella. 2014. Review of influenza a virus in swine worldwide: A call for increased surveillance and research. Zoonoses and Public Health 61: 4-17.

Vincent, A.L., K.M. Lager, B.H. Janke, M.R. Gramer, and J.A. Richt. 2008. Failure of protection and enhanced pneumonia with a US H1N2 swine influenza virus in pigs vaccinated with an inactivated classical swine $\mathrm{H} 1 \mathrm{~N} 1$ vaccine. Veterinary Microbiology 126: 310-323.

Watson, S.J., P. Langat, S.M. Reid, T.T. Lam, M. Cotten, M. Kelly, K. Van Reeth, Y. Qiu, G. Simon, E. Bonin, E. Foni, C. Chiapponi, L. Larsen, C. Hjulsager, I. Markowska-Daniel, K. Urbaniak, R. Durrwald, M. Schlegel, A. Huovilainen, I. Davidson, A. Dan, W. Loeffen, S. Edwards, M. Bublot, T. Vila, J. Maldonado, L. Valls, I.H. Brown, O.G. Pybus, and P. Kellam. 2015a. Molecular epidemiology and evolution of influenza viruses circulating within European swine between 2009 and 2013. Journal of Virology 89: 9920-9931.

Watson, S.J., P. Langat, S.M. Reid, T.T. Lam, M. Cotten, M. Kelly, K. Van Reeth, Y. Qiu, G. Simon, E. Bonin, E. Foni, C. Chiapponi, L. Larsen, C. Hjulsager, I. Markowska-Daniel, K. Urbaniak, R. Durrwald, M. Schlegel, A. Huovilainen, I. Davidson, A. Dan, W. Loeffen, S. Edwards, M. Bublot, T. Vila, J. Maldonado, L. Valls, E. Consortium, I.H. Brown, O.G. Pybus, and P. Kellam. 2015b. Molecular epidemiology and evolution of influenza viruses circulating within European swine between 2009 and 2013. Journal of Virology 89: 9920-9931.

Wesley, R.D. 2004. Exposure of sero-positive gilts to swine influenza virus may cause a few stillbirths per litter. Canadian Journal of Veterinary Research 68: 215-217.

Wiriyarat, W., H. Lerdsamran, P. Pooruk, R.G. Webster, S. Louisirirotchanakul, P. Ratanakorn, K. Chaichoune, K. Nateerom, and P. Puthavathana. 2010. Erythrocyte binding preference of 16 subtypes of low pathogenic avian influenza and 2009 pandemic influenza a (H1N1) viruses. Veterinary Microbiology 146 (3-4): 346-349. https://doi.org/10.1016/j.vetmic.2010.05.031.

Xie, Z., M. Zhang, L. Xie, S. Luo, J. Liu, X. Deng, Y. Pang, and Q. Fan. 2014. Identification of a triple-Reassortant $\mathrm{H} 1 \mathrm{~N} 1$ swine influenza virus in a southern China pig. Genome Announcements 2: e00229-e00214.

Yang, H., Y. Chen, C. Qiao, X. He, H. Zhou, Y. Sun, H. Yin, S. Meng, L. Liu, Q. Zhang, H. Kong, C. Gu, C. Li, Z. Bu, Y. Kawaoka, and H. Chen. 2016. Prevalence, 
genetics, and transmissibility in ferrets of Eurasian avian-like H1N1 swine influenza viruses. Proceedings of the National Academy of Sciences of the United States of America 113: 392-397.

Yang, J.R., C.Y. Kuo, H.Y. Huang, F.T. Wu, Y.L. Huang, C.Y. Cheng, Y.T. Su, F.Y. Chang, H.S. Wu, and M.T. Liu. 2014. Newly emerging mutations in the matrix genes of the human influenza a(H1N1)pdm09 and a(H3N2) viruses reduce the detection sensitivity of real-time reverse transcription-PCR. Journal of Clinical Microbiology 52: 76-82.

Yu, H., G.H. Zhang, R.H. Hua, Q. Zhang, T.Q. Liu, M. Liao, and G.Z. Tong. 2007. Isolation and genetic analysis of human origin H1N1 and H3N2 influenza viruses from pigs in China. Biochemical and Biophysical Research Communications 356: 91-96.

Yu, H., Y.J. Zhou, G.X. Li, J.H. Ma, L.P. Yan, B. Wang, F.R. Yang, M. Huang, and G.Z Tong. 2011. Genetic diversity of H9N2 influenza viruses from pigs in China: A potential threat to human health? Veterinary Microbiology 149: 254-261.

Yu, H., Y.J. Zhou, G.X. Li, G.H. Zhang, H.L. Liu, L.P. Yan, M. Liao, and G.Z. Tong. 2009. Further evidence for infection of pigs with human-like H1N1 influenza viruses in China. Virus Research 140: 85-90.

Zhang, J.C., W.D. Liu, Q. Liang, J.L. Hu, J. Norris, Y. Wu, C.J. Bao, F.Y. Tang, P. Huang, Y. Zhao, R.B. Yu, M.H. Zhou, H.B. Shen, F. Chen, and Z.H. Peng. 2014. Spatial distribution and risk factors of influenza in Jiangsu province, China, based on geographical information system. Geospatial Health 8: 429-435.

Zu, R., L. Dong, X. Qi, D. Wang, S. Zou, T. Bai, M. Li, X. Li, X. Zhao, C. Xu, X. Huo, N. Xiang, S. Yang, Z. Li, Z. Xu, H. Wang, and Y. Shu. 2013. Virological and serological study of human infection with swine influenza a H1N1 virus in China. Virology 446: 49-55.

\section{Publisher's Note}

Springer Nature remains neutral with regard to jurisdictional claims in published maps and institutional affiliations.

Ready to submit your research? Choose BMC and benefit from:

- fast, convenient online submission

- thorough peer review by experienced researchers in your field

- rapid publication on acceptance

- support for research data, including large and complex data types

- gold Open Access which fosters wider collaboration and increased citations

- maximum visibility for your research: over $100 \mathrm{M}$ website views per year

At $\mathrm{BMC}$, research is always in progress.

Learn more biomedcentral.com/submissions 